\title{
The Blind Spots in Theory U: The Reconstruction of a (Change-) Management Fashion
}

\author{
$\underline{\text { Stefan Kühl }}$ \\ Published online: 24 Mar 2020
}

\section{ABSTRACT}

Following a long period where the concept of a learning organization was the most popular way to implement change projects, consultants have now begun to apply a programme known as Theory U. A description of Theory $U$ from a sociological perspective reveals that it has the typical structure of a management fashion. Theory $U$ resembles a management fashion in as much as it holds out the promise that an organization - all of society, or even simply one individual - will be better off than beforehand after it has run through the various phases of the change process.

\section{KEYWORDS: Theory U, management fashion, blind spots}

Following a long period where the concept of a learning organization was the most popular way to implement change projects, organizational developers and systemic consultants have now begun to promote concepts associated with Theory U. It is a phase model which is intended to allow all participants to achieve a desired state. The first phase, 'downloading' in the world, where, one sees through the eyes of conventional thinking begins at the upper left of an imaginary ' $U$ '. Descending down the left side of the ' $U$ ', this is followed by the phase of 'seeing' during which the voice of judgment is to be suspended and a fresh look taken at reality. During this phase the object is to open the mind. This is followed by the 'sensing' phase, during which all participants are supposed to connect with the field, immerse themselves, and view the situation as part of a whole, thereby achieving an opening of the heart. The goal of the subsequent phase is 'opening the will' and the phases of 'letting go' and 'allowing to arise', during which one is supposed to connect with the 'inner source'. When one has figuratively arrived at the bottom of the ' $U$ ', which is a place of inner silence, all participants are supposed to ask the question of who they are and what their tasks consist of. This is the 'presencing' process. Then, following a renewed 'opening of the heart' and a phase of 'condensation', the visions that have emerged from this 'deeper source' are to be crystallized. This is followed by a renewed 'opening of the mind' which is meant to permit the mutual exploration and development of the future through practical activity. In the final phase, called 'performing', innovations are to be shaped through a change in day-to-day practices (Scharmer, 2009b, p. 42).

An examination of Theory $U$ from a sociological perspective reveals that it has the typical structure of a management fashion (for a description of management fashions in general, see e.g. Abrahamson, 1991, 1996; Benders \& van Veen, 2001; Clark, 2004; Kieser, 1997). A management fashion is never satisfied with simply attempting to optimize organizations but holds out the promise of changing individuals and society (Newell et al., 2001). Another typical feature of management fashions is that their concepts are outfitted with the signals of scientific competence, the suggestion being that whatever has been proven scientifically is 
also helpful in organizational practice (Collins, 2012). Screening out conflicts of interests is likewise characteristic for management fashions. Lean management and business process reengineering, for example, emphasize the win-win situation involved for all participants and thereby systematically exclude conflicts of interest (Benders \& van Veen, 2001; Kühl, 2017b). In Theory U, it is primarily the special emphasis on the community aspect that serves this purpose. Theory $U$ also resembles a management fashion in as much as it holds out the promise that an organization - all of society, or even simply one individual - will be better off than before after running through the various phases of the change process. There is also a dominant purpose-rational notion in Theory $U$ that a change process should be driven by a previously defined target state (Kühl, 2017a).

The goal of this article is to use a critical sociological perspective to systematically elaborate the blind spots in Theory U. By identifying the blind spots, I seek to clarify this theory and move it beyond management fashion. Theory U seeks to shed light on the 'invisible dimension of the social process' with which each of us is occupied in daily life, whether consciously or not and the 'blind spot of the social sciences' (Scharmer, 2009a, p. 38). My purpose in writing this article is to draw upon sociology to include an even more abstract level of observation. In the spirit of sociologist Niklas Luhmann, the intent of this article is therefore to offer an explanation through clarification.

\section{Blind Spot: The Simultaneous Transformation of Nearly Everything}

Management fashions require a dramatic crisis as a point of departure. The current crisis, according to Theory $\mathrm{U}$, entails not just one individual executive, organization, or nation; instead, it is a societal crisis. While pressure around us increases and the degree of freedom decreases, the unintentional side effects and consequences of our actions are multiplying. A thriving global economy notwithstanding, three billion people are living in poverty. We are spending 'enormous resources on health care systems' that 'merely tinker with symptoms and are unable to address the causes of health and sickness in our society'. We also pour 'considerable amounts of money into our educational systems, but we haven't been able to create schools and institutions of higher education that develop people's innate capacity to learn' (Scharmer, 2007, p. 203). Theory U holds that we are living on a 'thin crust of order and stability [that] could blow up at any time' (Scharmer, 2009b, p. 1).

The reaction to this crisis is the proclamation that great transformations are necessary. In the framework of re-acting, re-structuring, re-designing, re-framing, and re-generating, the object is to perform completely new actions, create new structures, set up new processes, establish new thinking, and create a new self. It is not enough to change only organizations or individual aspects of them. The object is to change the self of the people involved and thereby to lift society overall to a new development level. Here we find a pattern of argumentation that is typical for management fashions. Initially, their point of departure are the changes that must take place in an organization, but they assert that along with them society as a whole will change for the better. There is talk of the micro-, meso-, macro-, and mundo-level of social systems that Theory $U$ can access and change (Scharmer, 2009b, p. 232).

Yet, a sociological perspective suggests Theory $U$ misses the mark in this regard. The central insight of systems theory is that social systems operate in entirely different ways at different levels (vgl. grundlegend Luhmann, 1975). A face-to-face interaction based on communication between people who are actually present functions entirely differently than a marketplace in which goods and services are exchanged. A family, with its orientation toward intimate communication, uses an entirely different rationale than an organization that is oriented 
toward communicating decisions or a protest movement that is communicating values. The changes in communication among members of a team also conform to entirely different principles than changes in society.

Theory U runs counter to what social systems theory refers to as 'social differentiation' because it primarily serves to clarify the position of individual people within teams or groups. Theory $U$ is vague in its attempts to describe how organizational or even social change can be accomplished. Ideas for societal change such as participating in online courses participating in virtual groups seem to be ineffective prescriptions for accomplishing such extensive changes, and fail to demonstrate a fundamental understanding of differentiation in modern societies.

Blind Spot: The Suspension of the Differences Between Science, Economics, Politics, and Religion

Theory $\mathrm{U}$ attempts to link new scientific insights with spiritual elements in a way that allows a new political, economic, and religious practice to emerge. It suggests that in the 'development of the fourth field of social becoming', or practitioners in business, researchers in science, and those seeking meaning in religion will come together and create a common field. Theory $U$ is presented as a new science which brings to light the 'invisible dimension of social processes' which 'each of us confronts on a daily basis'. To that end, Theory U holds that science must be guided by the 'will of wisdom' (Scharmer, 2009b, p. 14).

Theory U suggests is that good science is also good practice. This approach belongs in the tradition of a close nexus between science, business, politics, and religion. One need only think of the demands for a democratization of science (Feyerabend, 1983), the many reflections on how research could be conducted in the real world through action research (for an overview, see Greenwood \& Levin, 2007), or the assertion that scientific research could spread out over an extremely wide range of locations using the so-called 'Mode 2' approach (Nowotny et al., 2001). In the final consequence, the concept of Theory $\mathrm{U}$ amounts to a dedifferentiation of business, science, politics, and religion.

Yet sociological systems theory points out that subdomains of society develop their own rationales. It is a specific characteristic of modern society that economic, political, religious, and scientific orientations fragment into separate fields, as opposed to the Middle Ages and the Early Modern Age where they were fused (for a short overview, see Luhmann, 1977). Economics, with its monetary considerations, functions entirely differently than science with its truth orientation, politics with its power orientation, or religion with its offer of explaining the inexplicable. In systems theory, the concept used to describe this development in modern society is called functional differentiation.

Theory $U$ ultimately negates the differences in orientation of various subdomains of society by envisioning a process in which players from widely diverse fields create a common future through an undertaking that entails an amalgamation of business, politics, religion, and science. In his view, the same intellectual model that underpins his management concept, namely, a society that merges business, politics, religion, and science, will save the world. That may be an appealing dream, but it bears little relationship to developments in modern society. 
It is a typical feature of management fashions that structural conflicts of interest are negated. Theory U similarly treats participants in the change process as individuals, while the formulations used always target the whole. Theory U emphasizes that its considerations do not refer 'primarily to individual leaders' but 'to our distributed or collective leadership'. 'Leadership in this century', means 'shifting the field structures of collective attention . . . at all levels'. (Scharmer, 2009b, p. 19). Indeed, grappling with conflicts of interest is assigned to a phase of 'communicative action'. A phase of downloading during which autistic systems exchange polite phrases is followed by a phase of debate where adaptive systems confront divergent points of view (Scharmer, 2009b, p. 327). Here, we already see evidence of an aversion to debate as a form of dialogue when it is stated that the 'word debate' means 'beat down your opponent with words'. Participants in debates use their 'arguments to beat or best their opponent, defined as anyone with a different opinion'. While the 'quality of the conversation' in debates does make it possible to 'perceive differing views and perspectives', when it becomes necessary for 'team members to reflect on and change their basic habits of thought and guiding assumptions', a different quality of conversation becomes necessary. (Scharmer, 2009b, p. 271).

This is the point where Theory $U$ introduces the idea that 'communicative action' take place through reflective exploration in dialogue. The participants in the conversation are supposed to 'speak of themselves as part of the whole' and thereby move from 'defending to inquiring into viewpoints'. In the community, this is theorized to lead to the emergence of 'quiet, collective creativity', a 'creative flow', and an 'authentic self' (Scharmer, 2009a, p. 232). There is mention of forming a 'collective container' in which 'emerging impulses for the future [can be heard] in yourself, in others, and between you'. It also involves developing a common understanding of the new state of being (Scharmer, 2009b, p. 19). This community ideology supports the notion that if everyone passes through the cycle of Theory $U$ together, conflicts of interest between those involved will be reduced or even eliminated completely. It explains why Theory U envisions that the World Bank, the Chinese government, McKinsey Consulting, multinational corporations, and NGOs can go through Theory U together in a global process and overcome their conflicts of interest. Theory $U$ therefore ultimately advocates old collective ideologies that deny the existence of opposing interests between individuals, groups, organizations, or classes (for variations types of community ideologies, see Krell, 1994).

It is easy to understand the attraction of this ideology of community. The stronger the perception of opposing interests and lines of conflict, the stronger the need for integration and community. In this context, Nils Brunsson speaks of 'reverse coupling' (Brunsson, 2003, p. 206). For example, when a city council decides to reduce automobile traffic by $30 \%$ in 15 years, citizens accept that traffic is currently increasing. Launching an advertising campaign for 'Swedishness' makes it easier for a Swedish electronics company to transfer business locations to other countries. And by the same token it makes sense for the top executives of an organization to emphasize the 'community' of all by proclaiming catalogs of values, publishing mission statements, or launching change processes with Theory $U-$ while at the same time the centrifugal forces within an organization are steadily strengthening.

Sociologists possess an understanding for the functionality of this form of 'organizational hypocrisy' (Brunsson, 1989). Organizations depend on sprucing up their display side because otherwise conflicts with the environment would come too close to their core processes (Kühl, $\underline{2013}$, p. 138). Yet if organizations believe too deeply in what they present to the external 
world, then they inhibit opposing interests from being articulated at all, thereby undermining organizational learning processes. The strong community orientation espoused by Theory $U$ therefore carries the danger of this concept degenerating into a learning prevention theory (Kühl, 2018, p. 124).

\section{Blind Spot: Reliance on Purposive-rational Thinking}

At first glance, Theory $U$ is a traditional phase model. Like most phase models, it conveys the suggestion of progress. The individual, the team, the organization, the state or even an entire society - all of them - will be refined after passing through the various phases. A similarity can be seen with Karl Marx's phase model, whereby mankind, following life in a primitive society, must first pass through a slave society, then feudal society, and later capitalist society before it can overcome class distinctions in a communist society. Yet this suggestion of progress is often contained even in small management phase models. In the Plan-Do-CheckAct cycle, the object is first to set up plans for achieving previously defined goals, then implement the plans accordingly, check the results by examining whether the goals have been reached, and, if that is the case, to finally establish the procedure as a new standard in the organization.

Theory $\mathrm{U}$ takes the form classical phase models and integrates esoteric ideas and concepts that are popular in parts of the change management scene. In contrast to Plan-Do-Check-Act cycles and PCSAM processes, which have a somewhat technocratic feel, Theory $U$ is rich with the poetry of change. What is easily overlooked in light of the poetic language is that Theory U ultimately amounts to an esoteric variant of classical purposive-rational thinking. Even if it emphasizes that the ' $U$ ' functions as a holistic field and nonlinear process, one still sees how similar Theory $\mathrm{U}$ is to the PCSAM phase model, the Plan-Do-Check-Act cycle, and Kurt Lewin's Unfreeze-Moving-Refreeze model. Like these models, Theory U ultimately revolves around analyzing the present state, identifying problems, formulating common goals, developing new opportunities, trying them out, and then implementing them. Although Theory $U$ has its own content emphasis and indicates that its intent is not so much to borrow concepts that were developed elsewhere, its ideas represent a variation on other purposiverational management concepts.

Nevertheless, Theory $\mathrm{U}$ is ultimately dominated by the purposive-rational approach of viewing change in terms of a common purpose. The end product is a common goal, except that it is now referred to as forming a 'common intention' for which one would like to connect with others; a future that 'wants to evolve [through oneself]', a 'landing strip of the future' or 'opening innovation spaces' (Scharmer, 2009b, p. 204). Talk of goals is replaced with the notion that in addition to the self, what a person, group, or organization has become based on the course of its previous life, there is yet a second self, the person or the community that one would like to become in the future (Scharmer, 2009b, p. 27). Rather than speaking of goals that management is meant to reach, there is now talk that the essence of management is to obtain the highest possible future (Scharmer \& Käufer, 2008, p. 4). However, what is leadership supposed to represent other than orienting actions to targets or goals that were envisioned together?

This brings the pivotal question to the forefront - do organizations and the lives of human beings largely function in the way Theory $U$ construes them? It is well documented in organizational research that players often act in irrational ways as they pursue solutions for previously defined problems. All too often, the goals that have been set are unclear or contradictory; frequently, the best suited method of solving a problem is not known; and the 
composition of decision-making committees is often the result of happenstance. The idea proposed by Cohen et al. (1972) Klicken oder tippen Sie hier, um Text einzugeben. is that players link solutions and problems only loosely, sometimes even noncommittally. From this perspective, solutions often emerge organically and in idiosyncratic fashion. Although this is not always the case, Theory U's overreliance on purposive rationality belies organizational reality in many circumstances. The recasting of esoteric terminology in Theory $U$ conceals its reliance on purposive rationality. As a rule, political processes are not defined by the esoteric sequences depicted in Theory U. Organizational decision-making processes generally do not conform to the clear phases like the ones set forth in Theory U. Instead, these phases often run parallel to one another, and the processes often emerge organically.

\section{Conclusion}

Management methods wear down over time. Methods such as lean management, business process reengineering, and learning organizations enjoyed praise at the beginning their formulas. According to Luhmann (2000, p. 336), early in their introduction these methods have not yet been subjected to the 'acid test'. Yet, as these models are applied, weak spots ultimately emerge. Such is the case with Theory U. Although the model has some utility, it ignores key differences, in science, communities, and organizations, and relies too heavily on purposive rationality in its model. The benefit of Theory $U$ is that its rhetoric is particularly change oriented and therefore inspires the courage to make transitions. Organizations, it suggests, must to a very significant degree simply ignore the uncertainty that precedes every decision. Addressing its blind spots is necessary to cement its impact and prevent it from fading away like so many management fashions that have come before.

\section{Disclosure statement}

No potential conflict of interest was reported by the author(s).

\section{Notes on contributor}

Stefan Kühl is professor of sociology at the University of Bielefeld in Germany and works as a senior consultant for Metaplan, a consulting firm based in Princeton, Hamburg, Shanghai, Singapore, Versailles and Zurich. He studied sociology and history at the University of Bielefeld (Germany), Johns Hopkins University in Baltimore (USA), Université Paris-XNanterre (France) and the University of Oxford (UK). His focus of research consists of societal theory, work, industrial and organizational sociology, as well as interaction sociology.

\section{References}

- Abrahamson, E. (1991). Managerial fads and fashions: The diffusion and rejection of innovations. Academy of Management Review, 16(3), 586-612. https://doi.org/10.5465/amr.1991.4279484 [Crossref], [Web of Science ®], [Google $\underline{\text { Scholar] }}$

- Abrahamson, E. (1996). Management fashion. Academy of Management Review, 21(1), 254-285. https://doi.org/10.5465/amr.1996.9602161572 [Crossref], [Web of Science ${ }^{\circledR}$, [Google Scholar]

- Benders, J., \& van Veen, K. (2001). What's in a fashion? Interpretative viability and management fashions. Organization, 8(1), 33-53. 
https://doi.org/10.1177/135050840181003 [Crossref], [Web of Science ®], [Google Scholar]

- Brunsson, N. (1989). The organization of hypocrisy: Talk, decisions and actions in organizations. John Wiley \& Sons. [Google Scholar]

- Brunsson, N. (2003). Organized hypocrisy. In B. Czarniawska \& G. Sevón (Eds.), The northern lights: Organization theory in Scandinavia (pp. 201-222). Copenhagen Business School Press. [Google Scholar]

- Clark, T. (2004). Strategy viewed from a management fashion perspective. European Management Review, 1(1), 105-111. https://doi.org/10.1057/palgrave.emr.1500004 [Crossref], [Web of Science [], [Google Scholar]

- Cohen, M. D., March, J. G., \& Olsen, J. P. (1972). A garbage can model of rational choice. Administrative Science Quarterly, 17(1), 1-25. https://doi.org/10.2307/2392088 [Crossref], [Web of Science ®], [Google Scholar]

- Collins, D. (2012). Management fads and fashions. In D. M. Boje, B. Burnes, \& J. Hassard (Eds.), The Routledge companion to organizational change (pp. 310-331). Routledge. [Google Scholar]

- Feyerabend, P. (1983). Science in a free society (2nd ed.). Verso Editions. [Google Scholar]

- Greenwood, D. J., \& Levin, M. (2007). Introduction to action research: Social research for social change (2nd ed.). Sage. [Crossref], [Google Scholar]

- Kieser, A. (1997). Rhetoric and myth in management fashion. Organization, 4(1), 4974. https://doi.org/10.1177/135050849741004 [Crossref], [Web of Science (1), [Google Scholar]

- Krell, G. (1994). Vergemeinschaftende Personalpolitik: Normative Personallehren, Werksgemeinschaft, NS Betriebsgemeinschaft, Betriebliche Partnerschaft, Japan, Unternehmenskultur. Rainer Hampp Verlag. [Google Scholar]

- Kühl, S. (2013). Organizations: A systems approach. Gower. [Google Scholar]

- Kühl, S. (2017a). Developing strategies: A very brief introduction. Organizational Dialogue Press. [Google Scholar]

- Kühl, S. (2017b). When the Monkeys Run the Zoo: The Pitfalls of Flat Hierarchies. Organizational Dialogue Press. [Google Scholar]

- Kühl, S. (2018). The rainmaker effect: Contradiction of the learning organization. Organizational Dialogue Press. [Google Scholar]

- Luhmann, N. (1975). Interaktion, organisation, gesellschaft. In N. Luhmann (Ed.), Soziologische Aufklärung 2 (pp. 9-20). WDV. [Crossref], [Google Scholar]

- Luhmann, N. (1977). Differentiation of society. Canadian Journal of Sociology / Cahiers Canadiens de Sociologie, 2(1), 29-53. https://doi.org/10.2307/3340510 [Crossref], [Web of Science ®], [Google Scholar]

- Luhmann, N. (2000). Organisation und Entscheidung. WDV. [Crossref], [Google $\underline{\text { Scholar] }}$

- Newell, S., Robertson, M., \& Swan, J. (2001). Management fads and fashions. Organization, 8(1), 5-15. https://doi.org/10.1177/135050840181001 [Crossref], [Web of Science ${ }^{\circledR}$ ], [Google Scholar]

- Nowotny, H., Scott, P., \& Gibbons, M. T. (2001). Re-thinking science: Knowlwedge and the public in an age of uncertainty. Polity Press. [Google Scholar]

- Scharmer, C. O. (2007). Theorie U: Von der Zunkunft her führen: Presencing als evolutionäre Grammatik und soziale Technik für die Erschliessung des vierten Feldes sozialen Werdens. Gesprächspsychotherapie Und Personzentrierte Beratung, 4, 202211. [Google Scholar] 
- Scharmer, C. O. (2009a). Theorie U: Von der Zukunft her führen; Presencing als soziale Technik. Carl Auer. [Google Scholar]

- Scharmer, C. O. (2009b). Theory U: Leading from the future as it emerges: The social technology of presencing. Berrett-Koehler; McGraw-Hill. [Google Scholar]

- Scharmer, C. O., \& Käufer, K. (2008). Führung von der leeren Leinwand: Presencing als soziale Technik. Organisationsentwicklung, 2, 1-8.

https://www.ottoscharmer.com/sites/default/files/2008_ZOE_01_Scharmer_NEU.pdf [ Google Scholar] 